\title{
Adopting E-training and Living Labs for Collaborative Learning for Rural Public Agencies
}

\author{
Ntaliani M. ${ }^{1}$, Costopoulou C. ${ }^{2}$
}

\begin{tabular}{|c|c|}
\hline I N F O & A B S T R A C T \\
\hline Received 16 Sept. 2010 & \\
\hline Accepted 10 Dec. 2010 & Rural Small and Medium Enterprises devote significant resources exclusively for finding \\
\hline Available on-line 3 Apr. 2013 & information so as to perform public services. The current period of information \\
\hline Responsible Editor: A. B. & technology achievements but also financial crisis necessitates a different approach by \\
\hline Sideridis & $\begin{array}{l}\text { local agencies and regional public authorities so as to provide information to rural } \\
\text { businesses. In this paper, a European project entitled "Rural Inclusion" aiming at making }\end{array}$ \\
\hline $\begin{array}{l}\text { Keywords: } \\
\text { collaborative learning, } \\
\text { agricultural public authorities, } \\
\text { electronic government. }\end{array}$ & $\begin{array}{l}\text { the life of civil servants and rural entrepreneurs easier through innovative e-government } \\
\text { services, training tools and methods is presented. In particular, this project offers } \\
\text { collaborative learning for public authorities on providing information and adopting and } \\
\text { deploying innovative e-government services, aiming at reducing the administrative } \\
\text { burdens of rural businesses. In this light, this paper presents a framework for public } \\
\text { authorities' training so as to model and provide information and e-government services. }\end{array}$ \\
\hline
\end{tabular}

\section{Introduction}

Rural Small and Medium Enterprises (SMEs) devote significant resources exclusively for finding information on public services. A great part of this information regards the informational phase, namely things that a rural SME should know before executing a particular public service. For instance, the informational phase concerns the SME's eligibility to perform a service; the Public Authorities (PAs) that are responsible for it; and what kind of documents the SME should adduce so as to apply for it. The process of searching for and retrieving this knowledge, either performed by the rural SME or by an expert (e.g. accountant, lawyer) on the rural SME's behalf, costs in terms of time and money. In many cases, this process can be repeated several times throughout a year, due to change of laws and regulations or in need of clarifications. Moreover, a public service could be very complex and include other public services, thus requiring information for each of them. For example in Latvia, the public service "Starting up a new business" requires performing five steps, namely decide on the foundation; paying the equity capital; register in the Register of Enterprises; open a bank account; and register in the State Revenue Service. The last two steps comprise on their own two individual public services (Ntaliani et al., 2011).

Administrative Burdens (ABs) are closely related with the informational phase of a public service. $\mathrm{ABs}$ are costs incurred by businesses for collecting information so as to meet legal obligations. In 2007, the European Commission (EC) launched the "Action Programme for Reducing Administrative Burdens in the European Union”, setting the grounds for the cooperation with the member states to reduce ABs on businesses. The Action Programme focuses on the identification of information obligations that incur serious ABs so as to be reduced. It focuses on thirteen selected priority areas including company law, employment relations, taxation/VAT, statistics, agriculture, and transport. It has been estimated that administrative costs can be cut down by a quarter by 2012, which in turns will increase the EU GDD by 1.4 (EC, 2009).

\footnotetext{
${ }^{1}$ NTALIANI, Maria

Informatics Laboratory, Agricultural University of Athens, 75 lera Odos, 11855 Greece

ntaliani@aua.gr

${ }^{2}$ COSTOPOULOU, Constantina

Informatics Laboratory, Agricultural University of Athens, 75 lera Odos, 11855 Greece

tina@aua.gr
} 
On the other hand, European countries have followed quite similar paths to reduce ABs as part of their efforts to modernize and reform their administration and improve the business environment and the quality of regulation. Rural SMEs consider ABs as the second most important individual business constraint, which justifies the raised interest by international organizations, PAs and the EU for measuring those (Costopoulou and Ntaliani, 2010).

The current period of information technology achievements but also financial crisis necessitates a different approach by PAs for providing information to rural SMEs and lowering their ABs. Such an approach is the Living Labs. Although Living Labs are a new phenomenon, there are various relevant definitions in literature. The Living Lab concept is based on a systematic user co-creation approach integrating research and innovation processes. According to Mitchell, a Living Lab represents a usercentric research methodology for sensing, prototyping, validating and refining complex solutions in multiple and evolving real life contexts (Kusiak, 2007). Bergvall-Kareborn et al. (2009), consider a Living Lab as a user-centric innovation environment built on every-day practice and research, with an approach that facilitates user influence in open and distributed innovation processes engaging all relevant partners in real-life contexts, aiming to create sustainable values. Also, they define as the five key components of a Living Lab the following: ICT and infrastructure, management, partners and users, research, and the approach. Particularly the approach is considered as the methodology or innovation approach for a Living Lab, which has five principles, namely openness, influence, realism, value and sustainability. Since PAs are usually responsible for overall innovation systems, they should not only be involved in Living Lab operation, but also utilize them from a content and application perspective in order to improve their transactions with businesses and internal workflow. (Niitamo et al., 2006).

In the RI context, the term "rural Living Lab" is used. It regards the involvement of rural users throughout all innovation processes; thereby, the innovation system becomes rural user-centric, in contrast to technology-centric. "Rural-Inclusion (RI): e-Government Lowering Administrative Burdens for Rural Businesses" (www.rural-inclusion.eu) is a project supported by the EC under the Competitiveness and Innovation Framework Programme. It aims at deploying an innovative infrastructure (e.g. software, models, and services) that will facilitate the offering of Semantic Web services by PAs in rural areas for the informational phase. In particular, RI aims at addressing PAs' longstanding challenges, such as easing the discovery of public services by users (rural SMEs), personalizing the service that the user needs to have access, providing all necessary information for the execution of the particular services and checking the eligibility of the user for receiving the service. Also, RI proposes a learning framework for helping PAs in implementing e-government services for supporting the informational phase. For succeeding these objectives, RI adopts, adapts, and deploys in a rural setting the Service Oriented Architecture (SOA) paradigm, implemented through state-of-theart Semantic Web technology and supported by rigorous and reusable public administration domain analysis and modelling while being in line with all major European programmes and initiatives.

The envisaged potential users of the RI services are in five European rural regions, rural Spain, the Greek island of Chios, rural Latvia, rural France and overseas, in the region of Martinique. On a regional/national level, the directly involved user groups will be rural SMEs - including SMEs, PAs, and e-government service technology providers and innovators. In addition, project results are expected to reach and involve - but are not limited to - the following beneficiaries:

- Development agencies: different types of development agencies supporting rural communities;

- Chambers: all types of sectoral or regional chambers (e.g. commerce, technical);

- Public organizations: all public authorities/agencies;

- Civil servants: employees of public organizations, especially the ones that are specialized in the public service in question;

- Rural SMEs: all rural SME and business audiences (i.e. professional unions/associations, co operations);

- Potential entrepreneurs or SME staff: future business audiences;

- Academia: scholars and students engaged in higher education and research; 
- Funding organizations: all types of financial organizations and funding agencies (e.g. banks, venture capitals, sponsors);

- Mediators: organizations playing a mediating role between public organizations and SMEs; and

- Non Governmental Organizations (NGOs): NGOs active in rural areas (focusing on particular groups of people, civil purpose/society).

The objective of the paper is to introduce a framework for PAs' training so as to model and provide information and e-government services for reducing the rural SMEs' ABs in the context of RI. Therefore, the structure of the paper is as follows: in section 2, the framework, as well as its application for two public services is described. The framework has two dimensions, namely etraining tools and collaborative learning. Section 3, explains in detail three training tools and the relevant training content for PAs. Section 4 presents two collaborative training initiatives, which are workshops and rural Living Labs. Finally, some conclusions are apposed.

\section{RI initiative for facilitating public services}

\subsection{E-government services}

RI project has already implemented the informational phase of nine public services (see Table 1). The public services have been documented and modelled according to the Public Service Modelling (PSM) methodology (D2.1, 2009). The implementation of the public service regards the development of a dialogue between the user of the public service (e.g. citizens/businesses) and the PA. Further below, two examples have been selected to present this approach, namely the "Issuing an operation license for manufacturing companies" service and the "Provision of grant to new farmers" service. The first one concerns different types of rural SMEs (e.g. food companies), whereas the latter is specialized for the agricultural sector. Both services concern the Greek island of Chios.

Table 1. Public services implemented by RI per region/country

\begin{tabular}{|c|c|}
\hline Region/Country & Public Service \\
\hline \multirow[t]{3}{*}{$\begin{array}{l}\text { Chios island/ } \\
\text { Greece }\end{array}$} & Registration in the Chios Chamber of Commerce \\
\hline & Provision of grant to new farmers \\
\hline & $\begin{array}{l}\text { Issuing an operation license for manufacturing } \\
\text { companies }\end{array}$ \\
\hline \multirow[t]{2}{*}{ Latvia } & Registration in the Register of Enterprises \\
\hline & Registration in the State Revenue Service \\
\hline \multirow[t]{2}{*}{ Spain } & $\begin{array}{l}\text { Identification of suitable business type for starting } \\
\text { up a business }\end{array}$ \\
\hline & $\begin{array}{l}\text { Provision of grant from SRE public agency to } \\
\text { unemployed persons for starting up a business }\end{array}$ \\
\hline Martinique/ France & Declaration of work accident \\
\hline France & Declaration employment of a new employee \\
\hline
\end{tabular}

\subsubsection{Issuing an operation license for manufacturing companies}

In Chios Island, a very significant cultivation is mastic. There is a great variety of products that are produced or contain mastic, such as cosmetics, pharmaceuticals and food. Thus, farmers cultivating 
mastic start up small and medium manufacturing companies in order to use mastic as a raw material for the production of other products. Therefore, it is very important to support local entrepreneurship via the provision of an electronic service about the issuance of an operation license for manufacturing companies. In order to receive an operation licence an entrepreneur has to submit relevant papers (e.g. questionnaire filled in by the owner of the company, approval of environmental condition, verification of land use, and technical memo) to the Manufacturing Department of the Chios Prefecture, which will check them so as to issue the licence. In order to find this information the rural SME has to ask PAs (Chios Chamber of Commerce) or read complex laws and regulations. With the RI approach, all this information is given to the farmer through a single source in a dialogue form (D2.3, 2010). Below we appose some of the dialogue questions:

- Where will the company be established?

- Will the company process flammable or toxic material or gas?

- Is the company's mechanical equipment load less that $22 \mathrm{KW}$ kinetic power or $50 \mathrm{KW}$ thermal power?

- Which is the cost of the company's mechanical equipment and the machinery load?

\subsubsection{Provision of grant to new farmers}

In order to apply for receiving a grant as a new farmer, information on how to obtain and/or fill in a number of official documents, namely the liquidation note and family status certificate from the Tax Office and the Municipality respectively, as well as the farmers' candidacy file, is needed. Also, particular information on preconditions for being eligible for the service is vital for the farmer. These preconditions are defined by a ministerial decision and concern the new farmer (e.g. regarding place of residence, military obligations) and the agribusiness (e.g. economic size, property regime) (Ntaliani et al., 2010). Below we appose some of the RI dialogue questions that are posed to the farmer so as to acquire the particular information:

- Are you a physical or legal entity?

- What is your age?

- Is the agricultural holding at your place of residence?

- Has the entire agricultural holding being declared in the last two years?

- Which is your permanent place of residence?

In both aforementioned examples, the questions show the facilitation of the process of finding information. Through the RI dialogical way it is very easy for rural SMEs and/or farmers that are not used to read official documents to understand laws and provide the necessary information for making applications and using public services. According to the answers of the rural SME and/or farmer the information is personalized for the particular service. The implementation of the informational phase of the two public services can be accessed from the Chios Chamber of Commerce at http://www.chioschamber.gr/xios/shared/rural.jsp?context=101 (in Greek). The ultimate objective of the project is to train PA employees to deploy the informational phase of the public services provided by their agency using the RI methodology. This is succeeded through a particular training framework, presented in the next section.

\subsection{RI framework}

PAs are the responsible bodies for serving citizens' and businesses' needs regarding their transactions with government. In order to succeed this, PA employees have to be trained. RI offers an innovative training framework for training not only PA employees, but also rural SME personnel, who are the receivers of public services, so that the RI services can be effectively introduced in rural settings. This framework is comprehensive and integrates actions benefiting both PA staff and rural SMEs personnel, and integrates the proposed e-government solution in a wider vision: to provide to people in rural areas ICT-enabled tools so that they can adopt and be able to adapt the proposed change, inventing their own solutions for their specific circumstances, in a continuous sustainable route towards capacity building in the rural community through a lifelong learning culture. 


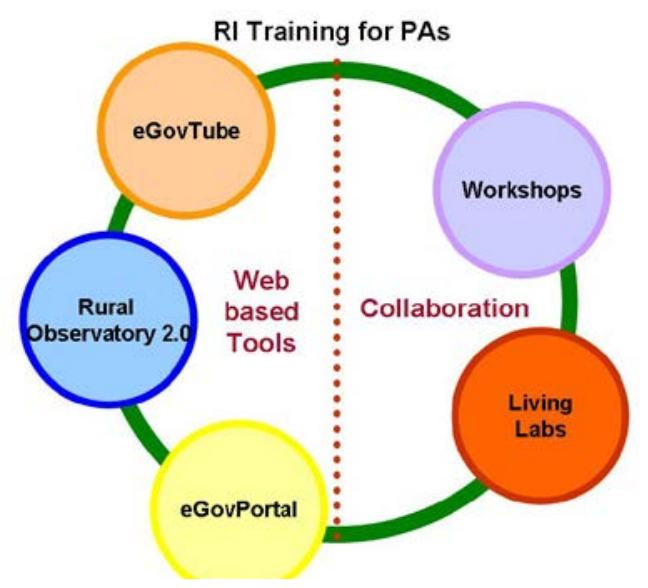

Figure 1. Training Framework for Public Agency Employees

As described in Fig. 1, RI provides a training framework through a multistage process including elearning tools and collaborative training. E-training tools regard three main platforms, namely the eGovTube, the Rural Observatory 2.0 and the Semantic eGovPortal tools. Collaborative training refers to a series of Living Labs and workshops where PA employees will have a collaborative learning experience through the use of the Web-based tools of the project. The main target participants of the training sessions are representatives of the local authorities and public service providers, who can also act as facilitators/observers.

\section{3. e-Training Public Agencies}

\subsection{Web-based tools}

PA employees are trained in using three Web-based tools, described as follows:

- eGoveTube (www.calt.insead.edu/eis/egovtubeen) is a collaborative Web 2.0-oriented platform that aims at supporting PAs in sharing information and experiences, identifying innovative services and developing users' interest for them, and using innovative eGov-supportive technology introduced by RI through video communication, community and knowledge assets network(s) visualisation, rich profiling and other tools (Luccini and Angehrn, 2010). eGovTube is used as core driver for sustaining the overall process, not only by giving room to the delivery of training content, but also by giving voice to all participants to share their ideas and experiences, so that the innovation diffusion process will be constantly challenged and assessed. This platform is able to deliver formal training content as well as informal, actionable learning-based activities. It offers 4 coupled environments (video space, rich profiling space, knowledge and social networks visualization tool, synchronous and asynchronous communication space), as well as other peculiar Web 2.0 features, such as rating and recommending, devised to sustain the RI community over time in fostering the reduction of the $\mathrm{ABs}$ and the adoption of innovative e-government technologies.

- Rural Observatory 2.0 (www.rural-observatory.eu/index.htm) is an innovative sophisticated Webbased environment that will facilitate information retrieval, access, usage and exploitation of egovernment services and relevant digital educational content (Manouselis et al., 2007; Karamolegkos et al., 2010). It is an online point of reference, which PAs can continuously access for relevant information and digital training resources. The use of the Rural Observatory 2.0 tool can allow to store and deliver more traditional training content, which may be useful for addressing PA employees' needs regarding specific topics.

- $\quad$ GovPortal is a platform that offers an ontology-based structured dialogue for driving users in eliciting specific information for performing a public service. It offers the main bundle of semantic e-government services and undertakes the responsibility of reducing the ABs of rural SMEs, in regard to their transactions with local authorities and regional public authorities (Ntaliani et al., 2012). 


\subsection{Training content}

Training content is a very vital means so as to disseminate the RI knowledge to interested beneficiaries. The training content is used in the workshop sessions and Living Labs that will be attended by the PAs' employees in the context of the RI project. In order to create the training content that would achieve the aforementioned workshop objectives a four-step process was followed: (a) identification of the PA's needs to be covered by training content; (b) collaboration with RI partners for collecting content; (c) selection of the resources that will be used as training content; and (d) categorization of the resources according to the training objective they fulfil.

These steps have led to the determination of 21 learning activities that represent the corresponding leaning objects. A learning object/resource is any entity, digital or non-digital, that may be used for learning, education or training. Learning objects should include some learning objectives and outcomes, assessments, and other instructional components, as well as the object itself (Patrikakis et al. 2008; Costopoulou et al., 2010). The determination of the particular learning activities is the result of collecting, integrating and/or adapting existing digital content provided by methodological partners in each country so as to address the needs of the RI PA training sessions.

The objective of training PAs on documenting and modelling public services using the RI methodology and tools has been achieved through the creation of fifteen (15) learning objects/ activities. Training content on exploiting the possibilities of eGovTube aims at supporting the following PA workshop activities: introduction to Web 2.0 and its relevance for RI for sustaining innovation adoption; eGovTube presentation to PA representatives, guided familiarization to rich profiling and to network navigation and exploration of eGovTube features on supporting submission and sharing of content. Three (3) learning objects/ activities have been created so as to support eGovTube . Also, two (2) and one (1) learning objects/ activities have been created for exploiting the possibilities of RuralObservatory 2.0 and eGovPortal correspondingly.

The training content has been mainly designed on non-technical and technical aspects. Analytically, the non-technical content concerns issues, such as public service modelling, examples on how to complete the public service template for a particular public service, as well as creating the relevant dialogues. The technical dimension concerns issues such as user manuals and web-based tool functionalities. The learning objects are distinguished into four subjects: (a) public service modelling; (b) using the eGovTube; (c) using the RuralObservatory 2.0; and (d) using the eGovPortal.

The learning objects have been analyzed by a set of characteristics, classified in three main categories, namely content characteristics, media type and format and usability and availability, as described below (Ntaliani et al., 2012):

\section{(i) Content characteristics}

- Subject coverage: The most important identification in regard to the training content is the different topics it covers. There are four main subjects, namely Public Service Modelling, Using eGovTube, Using RuralObservatory 2.0, and Using eGovPortal.

- Type: A learning object can be of one or more of the following types Application, Assessment, Case study, Demonstration, Educational, Glossary, Guide and Lecture (course/seminar).

- Content use: In regard to the potential use of the content, two possible uses were identified, namely informational use and use for training purposes.

- Quality procedures: An approach for the evaluation of the content quality, including structured questionnaires and interviews.

\section{(ii) Media type and format}

- Format: Learning objects are in various formats (e.g. videos, PowerPoint presentations, and MS Word documents) so as to offer a variety of means and attract more participants.

- Size: The analysis of content in respect to the storage capabilities revealed that the total of content does not have excessive requirements for storage. 


\section{(iii) Usability and availability}

- Ownership: For every learning resource the owner and creator/author have been identified.

It has to be noted that the creation of learning activities and corresponding learning objects is an on-going process throughout the whole RI project. This is due to the fact that gradually more egovernment services will be added in the RI platform. Moreover, the insights provided by PA employee workshops on the RI approach will lead to the evaluation of current training activities and to the suggestion of new ones that will cover successfully PAs' needs. The following section presents two collaborative learning initiatives, namely workshops and rural Living Labs.

\section{Collaborative training}

\subsection{Workshops}

Training events aim at training the PAs' personnel in specializing in using the RI services and tools, modelling services according to the project methodology, and assisting their community in taking up the services. Up till now, one small scale event per rural partner, as well as one large scale event in Greece, Martinique and France has been organized. Further workshops will be organized in order to address specific training needs that may emerge from the feedback and the input of the RI community posted in the eGovTube. The objectives of the workshops are to train the PAs in:

- Documenting and modelling public services using the RI methodology and tools;

- Using and exploiting the opportunities of eGovTube;

- Using and exploiting the opportunities of RuralObservatory 2.0;

- Using and exploiting the opportunities of eGovPortal.

The organized workshops will allow to provide direct tutoring on the RI tools that will foster the reduction of ABs related to public services and to gather insights from direct interaction from targeted users by the means of discussions and hands-on sessions. It concerns testing products and services in real time and real life environments, thus helping users to encounter, understand and solve the problems users encounter, and to detect the usable features that have to be promoted.

\subsection{Rural Living Labs}

The key concept behind the organization of a Living Lab is that the user should be involved in the innovation process all the time. Involving the users will enable the stakeholders to obtain products closer to the market requirements without having to create such a market, because the market is already there. The user can contribute with ideas, experiences and knowledge from his/her daily life and interactions with the products, services and applications. The fundament of a Living Lab is that the innovation system becomes human-centric, in contrast to the classic technology- and/or marketcentric approaches.

Observation of the behaviour of the users will provide information about the use of the tools, the obstacles to this use, and how to improve the usability of the tools and the ICT skills of the users. Recommendations, thus, will be based on real life experiences of the target group and therefore they will be context based and usable.

\section{Conclusions}

Nowadays, there are various platforms and initiatives for facilitating the communication of public agencies with citizens/ businesses using advanced ICT tools. For example, such a project is WeGov (wegov-project.eu). The particular project will develop a toolset that allows full advantage to be taken of a wide range of existing and well established social networking sites to engage citizens in two-way dialogs as part of governance and policymaking processes. In addition, Bose (2004), and Falivene and Silva (2008) identify training initiatives on e-government topics that mainly focus on the provision of necessary skills for the personnel of public and governmental agencies.

In this context, RI has the overall vision to make the life of civil servants and rural entrepreneurs easier through innovative e-government services, training tools and methods. Thus, it proposes a 
training framework through a multistage process developed as e-learning tools and collaborative training, where PA employees are trained and guided in an experiential learning process through the use of innovative Web-based tools. PA employees' training will bring them closer to the rural SMEs' needs so as to respond to them. Also, it tries to develop a lifelong learning-oriented digital culture, so that PA employees in rural areas will be able adopt, adapt and invent solutions for their specific circumstances, in a continuous sustainable route towards capacity building.

\section{Acknowledgements}

The work presented in this paper has been funded with support by the European Commission, and more specifically the project No 238900 "Rural-Inclusion: e-Government Lowering Administrative Burdens for Rural Businesses" of the ICT Policy Support Programme. This publication reflects the views only of the authors, and the Commission cannot be held responsible for any use which may be made of the information contained therein. The authors would like to thank all the consortium partners for their contribution in the design and implementation of this initiative.

\section{References}

Bergvall-Kareborn, B., C.Ihlström Eriksson, A. Stahlbröst, and J. Svensson. 2009. A Milieu for innovation defining Living Lab. 2nd ISPIM Innovation Symposium, New York, December 6-9.

Bose R. 2004. E-government: infrastructure and technologies for education and training. Electronic Government, an International Journal 1(4), 349-361.

Costopoulou, C., N. Manouselis, M. Ntaliani, and A. Tzikopoulos. 2010. Training agricultural tutors in digital learning repositories. In Proc. ITAFFE'10-3rd International Congress on Information and Communication Technologies in Agriculture, Food, Forestry and Environment, ISBN 978-975-7636-71-7, pp. 15-21.

Costopoulou, C. and M. Ntaliani. 2010. Measuring administrative burdens of e-government services for rural SMEs. In: Proc. 3rd World Summit on the Knowledge Society 2010, 23-25 September, Corfu, Greece, Communications in Computer and Information Science 112, pp.435-442, DOI: 10.1007/978-3-642-16324-1_52.

D2.1, 2009. Reference service model and modelling methodology for public services. Rural Inclusion Deliverable.

D2.3, 2010. Selection and documentation of public services. Rural Inclusion Deliverable.

European Commission. 2009 Enterprise and industry - better regulation. Retrieved from: http://ec.europa.eu/enterprise/policies/better-regulation/administrative-burdens/actionprogramme/index_en.htm\#h2-the-eu-standard-cost-model.

Falivene, G. and M. Silva. 2008. Reflections and proposals on public officials training and promotion of egovernment”, International Journal of Electronic Government Research, 4(2), 43-58.

Karamolegkos, P., A. Maroudas, N. Manouselis. 2010. Application profiling for rural communities: egov services and training resources in Rural Inclusion. Communications in Computer and Information Science 108: 46-56.

Kusiak, A. 2007. Innovation: The Living Laboratory perspective. Computer-Aided Design \& Applications, 4 (6), 863-876.

Luccini, M., and A. Angehrn. 2010. eGovTube: Web2.0 collaboration to sustain innovation adoption in rural living labs. In Proc. ICE 2010 16th International Conference on Concurrent Enterprising, Lugano, Switzerland.

Manouselis, N., A. Tzikopoulos, C. Costopoulou, and A. B. Sideridis. 2007. Training rural SMEs on using eGovernment services. In: Proc. 6th Biennial Conference of the European Federation of IT in Agriculture on Environmental and Rural Sustainability through ICT (EFITA/WCCA 2007).

Manouselis, N., K. Kastrantas, A. Tzikopoulos, C. Costopoulou, and A. B. Sideridis. 2008. Implementing an egovernment observatory for rural SMEs”. In: Proc. First World Summit on Emerging Technologies and Information Systems for the Knowledge Society (WSKS 2008), Springer, 5288 LNCS/LNAI, pp. 583-592.

Niitamo, V.P., S. Kulkki, M. Eriksson, and K. Hribernik. 2006. State-of-the-art and good practice in the field of living labs. Proceedings of the 12th International Conference on Concurrent Enterprising: Innovative Products and Services through Collaborative Networks, Milan, Italy, 349-357. 
Ntaliani, M., C. Costopoulou, and A. B. Sideridis, 2012. Alleviating SMEs’ administrative burdens: The Rural Inclusion Initiative, H. Jahankhani et al. (Eds): ICGS3 /e-Democracy 2011, Springer, 99LNICST, pp. 237-244.

Ntaliani, M., C. Costopoulou, A. M. Luccini, and A. B. Sideridis. 2011. Collaborative training for agricultural public authorities for innovative provision of information and services. In: Proc. European Federation for Information Technology in Agriculture, Food and the Environment / World Congress on Computers in Agriculture (EFITA/WCCA 2011).

Ntaliani, M., S. Karetsos, C. Costopoulou, E. Tambouris, and K. Tarabanis. 2010. Agricultural e-government services: an implementation framework and case study. Computers and Electronics in Agriculture 70(2), 337347.

Patrikakis, Ch., M., Koukouli, C., Costopoulou, and A.B. Sideridis. 2008. Content requirements identification towards the design of an educational portal. In: Proc. of the First World Summit on Emerging Technologies and Information Systems for the Knowledge Society (WSKS 2008), CCIS 19, pp. 253-260. 